\title{
RANCANG BANGUN MEDIA PEMBELAJARAN SENI DAN BUDAYA SUKU BANJAR BERBASIS AUGMENTED REALITY
}

\author{
Muhammad Edya Rosadi ${ }^{1)}$, Indu Indah Purnomo ${ }^{2)}$ \\ ${ }^{1,2)}$ Fakultas Teknologi Informasi, Universitas Islam Kalimantan Muhammmad Arsyad Al Banjari Banjarmasin \\ Jalan Adhyaksa No.2 Kayu Tangi Banjarmasin 70123 \\ e-mail: edya@uniska-bjm.ac.id ${ }^{1)}$, indu@uniska-bjm.ac.id ${ }^{2)}$
}

\begin{abstract}
ABSTRAK
Media pembelajaran yang bagus merupakan salah satu sarana penting penunjang pendidikan, dengan majunya teknologi saat ini menawarkan pembaharuan dalam pembuatan media pembelajaran. Salah satu bidang penting adalah pembelajaran seni dan budaya yang sangat beranekaragam di Indonesia, di mana saat ini mengalami penurunan antusiasme dari generasi muda untuk mempelajarinya. Hal ini dikarenakan media pembelajaran yang sama masih berbentuk 2 dimensi pada buku-buku pelajaran yang telah umum. Untuk mengatasi hal di atas salah satu teknologi yang semakin berkembang adalah augmented reality yang menawarkan fitur penggambaran objek menjadi lebih jelas dan rinci karena berbentuk 3 dimensi. Pada penelitian ini teknologi augmented reality diimplementasikan pada aplikasi android yang dapat menampilkan bentuk 3 dimensi antara lain rumah adat, alat transportasi, alat musik, pakaian tradisional dan senjata suku Banjar. Penggunaan rekayasa System Development Life Cycle (SDLC) dengan metode Waterfall untuk membuat aplikasi menjamin kualitas aplikasi yang dihasilkan. Diharapkan dengan adanya aplikasi ini minat dan pengetahuan anak-anak dalam belajar budaya dan kesenian daerah menjadi meningkat.
\end{abstract}

Kata Kunci: Augmented Reality, Budaya, Seni, Suku Banjar

\begin{abstract}
Good learning media is one of the important means of supporting education, with the advancement of technology now offering renewal in the making of learning media. One important area is the learning of a very diverse arts and culture in Indonesia, which is currently experiencing an enthusiastic decline from the younger generation to learn it. This is because the same learning media is still in 2 dimensions such as general textbooks. To overcome the above, one of the technologies that is increasingly developing is augmented reality that offers the object's depiction features to be clearer and more detailed because of its 3-dimensional shape. In this study augmented reality technology is implemented into an android application that can display 3-dimensional shapes including traditional houses, transportation, music tools, tradisional clothing and weapons of the Banjar tribe. The use of the System Development Life Cycle (SDLC) with the Waterfall method to make the application guarantee the quality of the application produced. It is expected that with this application, children's interest and knowledge in learning regional culture and art will increase.
\end{abstract}

Keywords: Art, Augmented Reality, Culture, Banjar Tribe

\section{PENDAHULUAN}

TEKNOLOGI yang berkembang sangat pesat sekarang ini ibarat pisau bermata dua, banyak membawa pengaruh positif namun tidak jarang pula membawa hal negatif. Tidak terkecuali dalam dunia pendidikan, kemudahan yang ditawarkan oleh teknologi tidak dapat dipungkiri menggeser cara belajar anak-anak yang lahir dan besar di era digital. Cara anak-anak yang menunjukkan identitasnya dengan membuat akun media sosial, generasi yang lebih terbuka dan berfikir lebih agresif, kebebasan dalam berekspresi, tidak suka diatur dan dikekang serta lebih sering mengakses secara langsung mesin pencari melalui internet dalam proses belajar adalah ciri anak-anak generasi digital[1].

Cara belajar ini tentu juga harus diikuti oleh media pembelajaran yang selaras, para pengajar dan peneliti terus bekerja sama mengembangkan media pembelajaran yang sesuai dengan kemajuan zaman. Salah satu teknologi yang sedang berkembang untuk dapat digunakan menjadi media pembelajaran adalah teknologi augmented reality (AR), dengan teknologi ini objek dunia maya dapat ditambahkan seolah-olah berada pada lingkungan nyata dalam bentuk 3 dimensi. Proyeksi bentuk 3 dimensi ini membuat objek-objek itu menjadi semakin menarik dan detail.

Di bidang pendidikan sendiri teknologi augmented reality telah banyak diimplementasikan, seperti aplikasi yang menggunakan media bantu buku augmented reality, permainan, pemodelan objek dan pembelajaran berdasarkan pengamatan[2]. Pada penelitian ini dirancang dan dibuat aplikasi android yang berisi seni dan budaya suku Banjar berbasis augmented reality, objek seni dan budaya yang dimodelkan 3 dimensi menjadi lebih sesuai untuk menarik minat anak-anak untuk belajar mengenal seni dan budaya daerah. Mengingat pentingnya bangsa kita untuk terus melestarikan kekayaan seni dan budaya Indonesia. 


\section{LANDASAN TEORI}

\section{1) Media Pembelajaran}

Media pembelajaran adalah segala sesuatu yang dapat digunakan untuk menyalurkan pesan dari pengirim ke penerima pesan. Dalam hal ini adalah proses merangsang pikiran, perasaan, perhatian, dan minat serta perhatian siswa sehingga proses belajar dapat terjalin[3].

\section{2) Augmented Reality}

Augmented reality atau yang sering disingkat AR adalah teknologi pencitraan yang memproyeksikan benda maya ke dalam dunia nyata dengan bentuk 2 atau 3 dimensi, teknologi ini biasa disebut juga dengan realitas tertambah. Pengguna akan melihat benda 2 atau 3 dimensi tersebut seperti disisipkan pada tampilan layar, untuk pengambilan gambar dunia nyata menggunakan kamera. Dengan bertambah bagusnya kualitas kamera pada telepon genggam membuat teknologi ini menjadi hiburan dan sarana baru baik dalam permainan atau media belajar dengan tujuan untuk menarik minat penggunanya.

\section{3) Vuforia}

Vuforia adalah salah satu aplikasi yang dapat digunakan untuk mengembangkan pembuatan augmented reality. Vuforia mempunyai kemampuan untuk melakukan pengenalan citra (image recognition), aplikasi ini telah mendukung sistem operasi android dan iOS dengan bentuk software development kit (SDK) yang memudahkan pengembang membuat dan mendesain aplikasi augmented reality sesuai imajinasi[4].

\section{4) Unity3D}

Unity3D adalah aplikasi untuk membuat bentuk objek 3 dimensi (3D), penggunaan pada pengembangan grafis permainan lebih diutamakan dengan aplikasi ini namun tidak menutup kemungkinan juga digunakan pada rancangan arsitektur dan animasi 3 dimensi. Platform yang didukung oleh Unity antara lain Windows, Unity Web, Mac, Android, iOS, Xbox, Playstation 3 dan Wii[5].

\section{Metode PENELITIAN}

\section{A. Metode Pengumpulan Data}

1.) Observasi

Pengumpulan data pertama adalah dengan observasi langsung untuk mendapatkan gambaran kesenian dan kebudayaan suku Banjar terutama bentuk rumah adat, kesenian dan senjata tradisional dengan mengunjungi museum Lambung Mangkurat Banjarbaru dan museum Wasaka Banjarmasin.

2.) Studi Pustaka

Pengumpulan data kedua dengan melakukan studi kepustakaan ke Dinas Perpustakaan dan Arsip Daerah Provinsi Kalimantan Selatan sebagai tempat mendapatkan referensi seni dan budaya Suku Banjar dalam bentuk narasi, yang akan dimuat dalam media buku sebagai alat bantu aplikasi augmented reality yang telah dibuat.

\section{B. Tahapan Penelitian}

Metode yang digunakan dalam penelitian ini yaitu metode System Development Life Cycle (SDLC) dengan model Waterfall, yang dapat dibagi lagi menjadi beberapa tahap yaitu analisa kebutuhan, desain sistem, implementasi, pengujian dan pemeliharaan.

\section{RANCANGAN MODEL SISTEM}

\section{A. Use Case Diagram}

Rancangan diagram kasus pengguna dari sistem yang dibuat ditunjukkan pada Gambar 1. Sistem memiliki 8 kasus pengguna yaitu, 1) Mulai Mode AR, 2) Tracking Marker, 3) Menampilkan Deskripsi Objek, 4) Menampilkan Objek, 5) Melakukan Kontrol Objek, 6) Panduan, 7) Tentang Aplikasi, 8) Tutup/Keluar Aplikasi. 


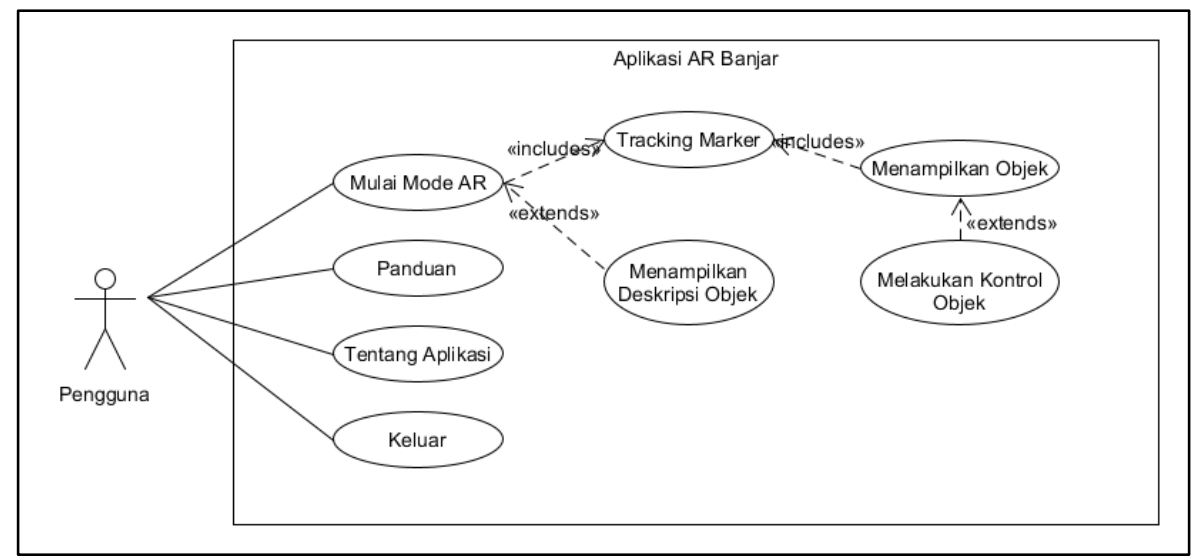

Gambar. 1. Use Case Diagram aplikasi Banjar AR

\section{B. Kategori Objek Terpilih}

Melalui proses observasi dan studi pustaka saat pengumpulan data, didapatkan banyak kebudayaan dan keseniaan suku Banjar. Misalnya rumah adat suku Banjar yang terbagi dalam 11 tipe[6], begitu juga dengan berbagai macam alat musik, alat transportasi tradisional dan senjata tradisional[7]. Seni dan Budaya Banjar yang sangat beragam, memberikan banyak pilihan untuk pembuatan objek-objek 3 dimensi yang akan dijadikan aset pada aplikasi augmented reality, berikut rancangan objek terpilih berdasarkan kategori dalam Tabel I.

TABEL I

RANCANGAN OBJEK TERPILIH UNTUK DIMASUKKAN KE DALAM APLIKASI

\begin{tabular}{cll}
\hline \hline No & \multicolumn{1}{c}{ Kategori } & \multicolumn{1}{c}{ Objek } \\
\hline 1 & Rumah Adat & - Rumah Banjar Bubungan Tinggi \\
& & - Rumah Lanting \\
\hline 2 & Alat Musik Tradisional & - Panting \\
\hline 3 & Transportasi Tradisional & - Jukung \\
\hline 4 & Kain Khas Daerah & - Sasirangan \\
\hline 5 & Senjata Tradisional & - Mandau \\
& & - Keris \\
\hline \hline
\end{tabular}

\section{IMPLEMENTASI SISTEM}

\section{A. Tampilan Aplikasi}

TABEL II

TAMPILAN APLIKASI BANJAR AR

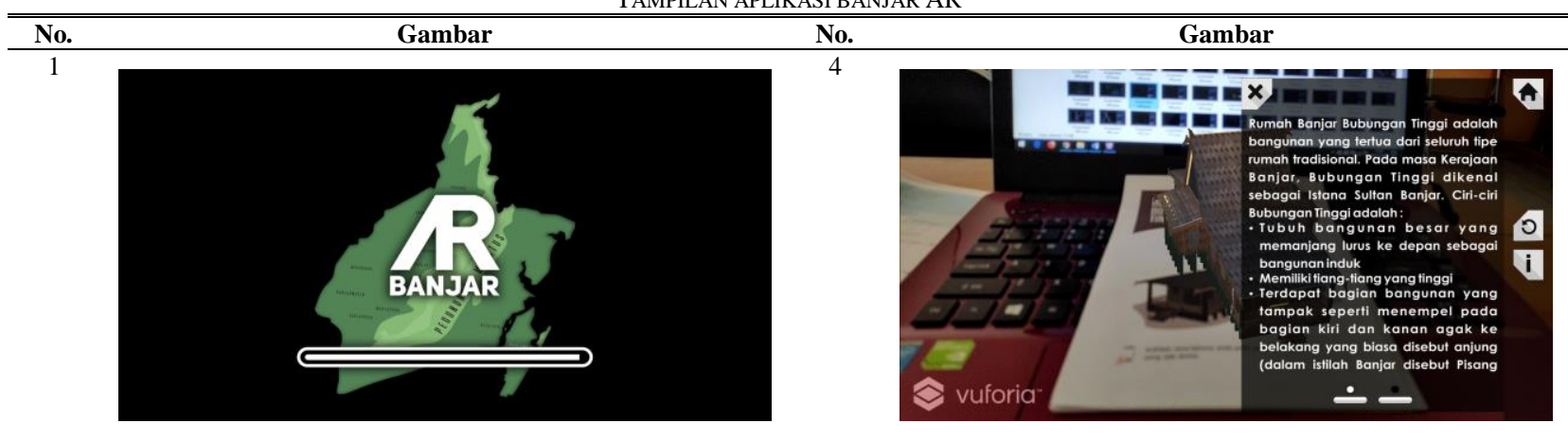




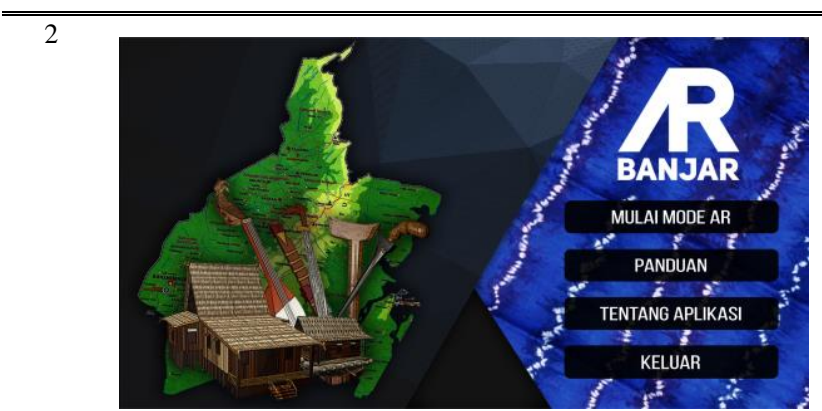

3

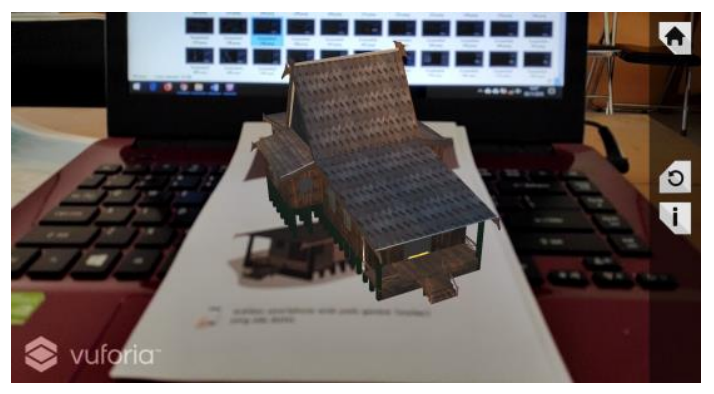

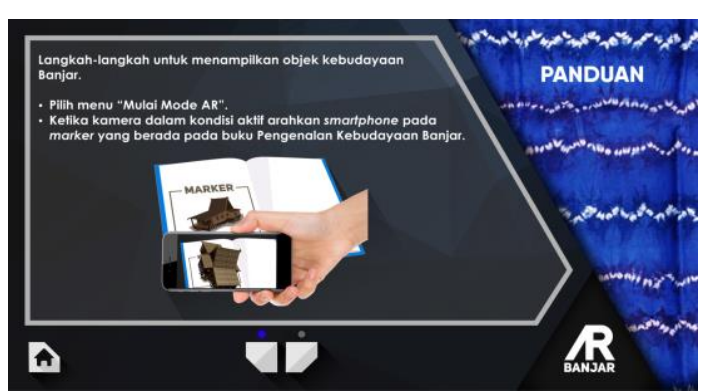

6

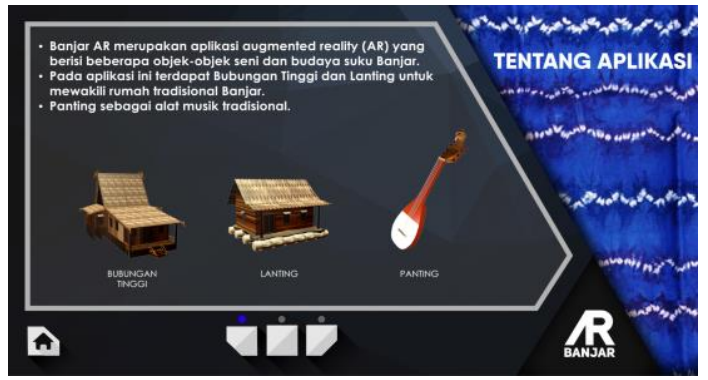

Tabel II merupakan tampilan aplikasi Banjar AR yang telah berhasil diimplementasikan, pada gambar 1 adalah tampilan splash screen yang akan tampil saat aplikasi awal dijalankan. Gambar 2 tampilan menu utama aplikasi yang terdiri dari tombol mulai mode AR, panduan, tentang aplikasi dan keluar. Gambar 3 adalah tampilan saat mode AR dijalankan, menggunakan akses kamera kemudian marker dipindai untuk menampilkan objek 3 dimensi (3D). Saat objek 3D telah tampil, maka pengguna dapat menekan tombol rotasi untuk memutar objek dan menekan tombol informasi (i) untuk melihat deskripsi dari objek yang ditampilkan seperti pada contoh gambar 4. Gambar 5 merupakan halaman panduan penggunaan aplikasi, yang akan tampil saat pengguna memilih menu panduan dan gambar 6 adalah tampilan halaman tentang aplikasi ketika pengguna memilih menu tentang aplikasi.

\section{B. Tampilan Lembar Pindai (Marker) Augmented Reality}

Aplikasi yang dibuat pada penelitian ini termasuk aplikasi augmented reality yang memerlukan marker (media pindai) untuk menampilkan objek 3 dimensi (3D). Jumlah marker yang sebanyak 7 (tujuh) buah, sesuai dengan perancangan kategori objek terpilih. Berikut ini tabel gambar marker dan keterangan objek yang akan ditampilkan ditunjukkan pada Tabel III.

TABEL III

TAMPILAN LEMBAR PINDAI (MARKER) AUGMENTED REALITY

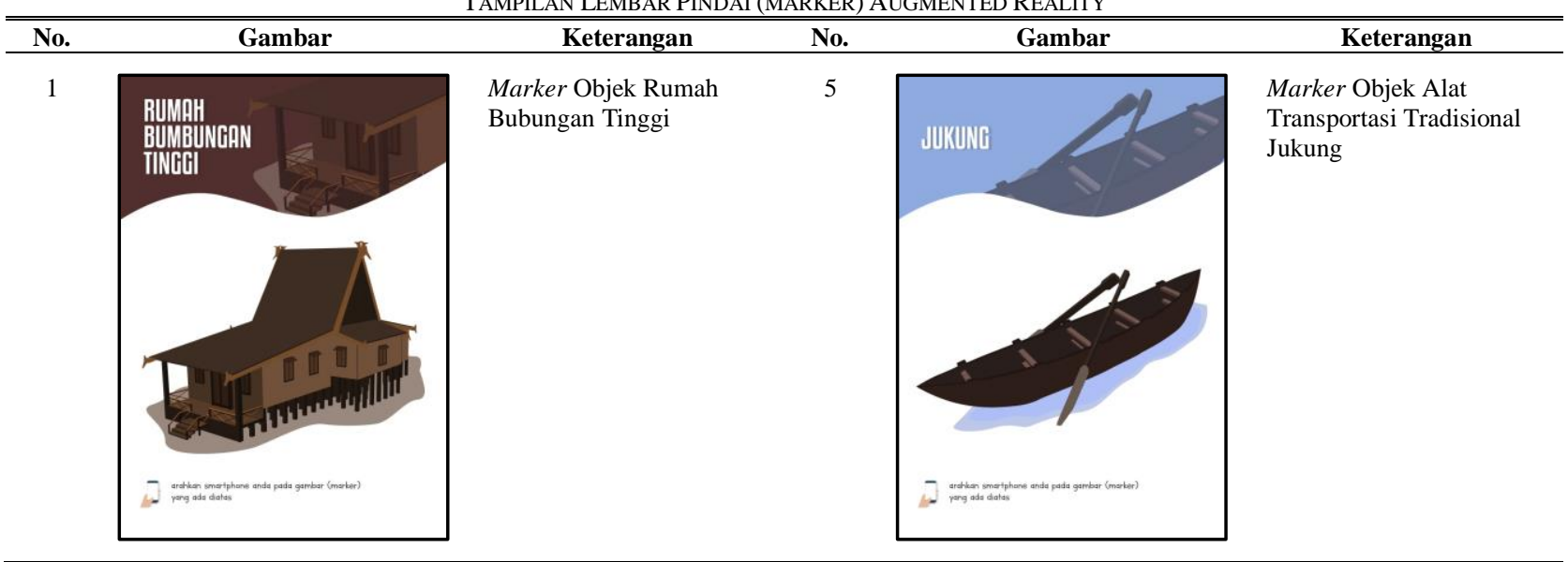


2

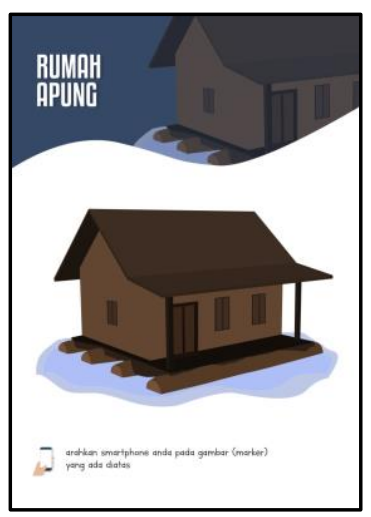

3

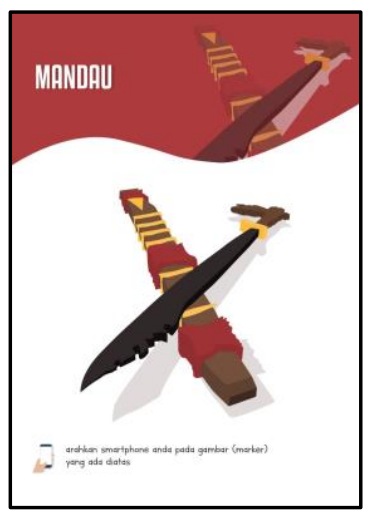

4

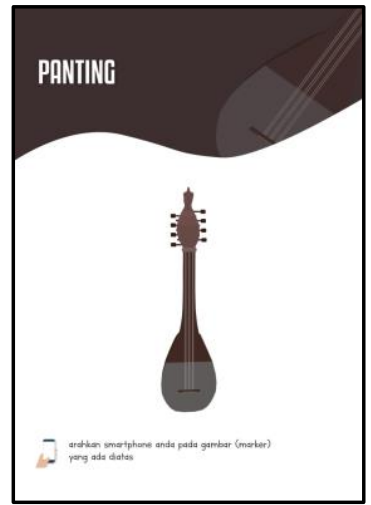

Marker Objek Rumah

Apung (Lanting)

Marker Objek Senjata

Tradisional Mandau

Marker Objek Alat Musik

Tradisional Panting

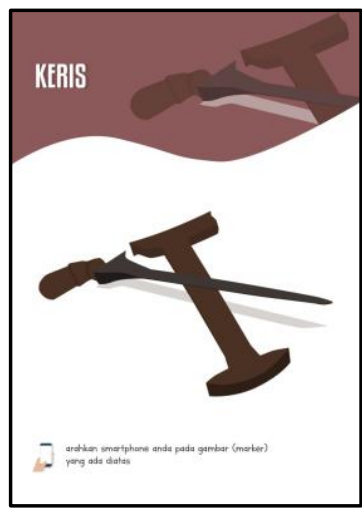

Marker Objek Senjata

Tradisional Keris

7

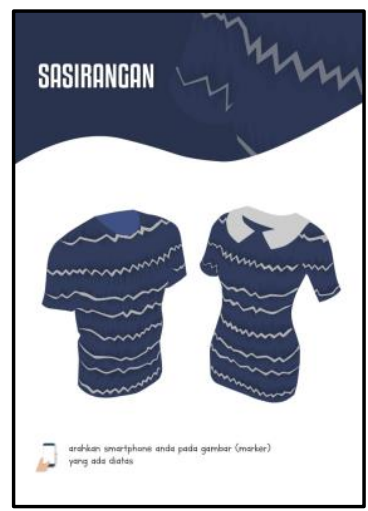

Marker Objek Kain Khas

Daerah Sasirangan

\section{Hasil Pengujian Aplikasi}

Untuk dapat menilai kesesuaian antara rancangan dan aplikasi yang dibuat, selanjutnya dilakukan pengujian dengan menggunakan metode Black Box Testing. Dari seluruh hasil pengujian dapat disimpulkan aplikasi telah sesuai dengan rancangan. Hasil pengujiannya ditunjukkan pada Tabel IV.

TABEL IV

HASIL PENGUJIAN BLACK BOX

\begin{tabular}{|c|c|c|c|}
\hline No & Skenario Pengujian & Hasil yang diharapkan & Kesimpulan \\
\hline 1 & Pemasangan Aplikasi BanjarAR & $\begin{array}{c}\text { Aplikasi Banjar AR dapat terpasang pada sistem android } \\
\text { dengan lancar }\end{array}$ & Berhasil \\
\hline 2 & Menjalankan Aplikasi BanjarAR & $\begin{array}{l}\text { Membuka aplikasi, muncul splash screen dan } \\
\text { berjalannya aplikasi dengan baik }\end{array}$ & Berhasil \\
\hline 3 & Menekan tombol "MULAI MODE AR" & $\begin{array}{c}\text { Terhubungnya kamera dan siap melakukan pemindaian } \\
\text { marker }\end{array}$ & Berhasil \\
\hline 4 & Menekan tombol "PANDUAN" & Tampil halaman panduan cara penggunaan aplikasi & Berhasil \\
\hline 5 & Memindai marker yang tidak sesuai & Tidak tampil objek 3 dimensi & Berhasil \\
\hline 6 & Memindai marker yang telah ditentukan (sesuai) & Tampil objek 3 dimensi sesuai marker & Berhasil \\
\hline 7 & Menekan tombol informasi saat pemindaian marker & Tampil informasi objek 3 dimensi sesuai marker & Berhasil \\
\hline 8 & $\begin{array}{c}\text { Menekan tombol rotasi pada saat objek } 3 \text { dimensi } \\
\text { muncul }\end{array}$ & Objek 3 dimensi berputar (berotasi) & Berhasil \\
\hline 9 & Menekan tombol "KEMBALI" & Kembali ke menu utama & Berhasil \\
\hline 10 & Menekan tombol "TENTANG APLIKASI" & Tampil halaman yang berisi deskripsi tentang aplikasi & Berhasil \\
\hline 11 & Menekan tombol "KELUAR" & Tertutup dan keluar dari Aplikasi BanjarAR dengan baik & Berhasil \\
\hline
\end{tabular}




\section{KESIMPULAN}

Berdasarkan pembahasan di atas, maka dapat diambil kesimpulan sebagai berikut:

1. Bentuk 3 dimensi (3D) yang telah dibuat dan diimplementasikan ke dalam aplikasi teknologi augmented reality tidak berbeda jauh dan dapat mewakili objek yang sesungguhnya, detail dan rincian setiap objek juga terlihat dengan baik.

2. Deskripsi yang ditampilkan saat objek 3D muncul, dapat menjadi penjelasan tambahan sehingga pengguna mendapat gambaran yang jelas terkait objek seni dan budaya tersebut.

\section{UCAPAN TERIMA KASIH}

Ucapan terima kasih disampaikan kepada DRPM Kementerian Riset, Teknologi dan Pendidikan Tinggi (KEMENRISTEKDIKTI) Republik Indonesia, Universitas Islam Kalimantan Muhammad Arsyad Al Banjari Banjarmasin, Museum Wasaka Banjarmasin, Musem Lambung Mangkurat Banjarbaru serta Dinas Perpustakaan dan Arsip Daerah Provinsi Kalimantan Selatan.

\section{DAFTAR PUSTAKA}

[1] Kementerian Pendidikan dan Kebudayaan. (2016). Seri Pendidikan Orang Tua: Mendidik Anak di Era Digital. Jakarta: Kementerian Pendidikan dan Kebudayaan

[2] Yuen, S. C.-Y. (2011). Augmented Reality: An Overview and Five Directions for AR in Education. Journal of Educational Technology Development and Exchange, 119-140

[3] Sadiman, A. S. (2008). Media Pendidikan. Jakarta: PT Raja Grafindo Persada.

[4] Vuforia. (2017, 7 2). Vuforia Developer Portal. Diambil kembali dari Vuforia Tersedia: https://developer.vuforia.com/

[5] Unity. (2017, 7 2). Unity - Game Engine. Diambil kembali dari Unity 3D Tersedia: https://unity3d.com/

[6] Seman, Syamsiar dan Irhamna. (2001). Arsitektur Tradisional Banjar Kalimantan Selatan. Banjarmasin: Ikatan Arsitek Indonesia Daerah Kalimantan Selatan

[7] Hendrawan, M.H. (2011). Materi Muatan Lokal Kebudayaan Banjar: Muatan Lokal. Kalimantan Selatan: Dinas Pemuda, Olahraga, Kebudayaan \& Pariwisata 